\title{
0 lugar dos sujeitos e a questão da hipossuficiência na promoção da saúde ${ }^{*}$
}

Juan Carlos Aneiros Fernandez ${ }^{1}$

Marcia Faria Westphal ${ }^{2}$

FERNANDEZ, J.C.A.; WESTPHAL, M.F. The place of subjects and the issue of hypo-sufficiency in health promotion. Interface - Comunic., Saude, Educ., v.16, n.42, p.595-608, jul./set. 2012.

This article discusses the notion of subject hypo-sufficiency that is present in texts focusing on health promotion. It presents the results from a doctoral study in which five doctoral theses and four master's dissertations on health promotion were reviewed. The analytical framework was built around the notions of social dynamics, the rationales used and visions relating to the project of modernity present in the material researched. From this, the etiologies for producing the concept of subject hypo-sufficiency and therefore the place that this production reserves for it can be interpreted.

Significant occurrences of this notion of hypo-sufficiency were observed and it was seen to approach scientism.

Keywords: Health promotion. Rationality. Subject. Epistemology.
Este artigo discute a noção da hipossuficiência do sujeito presente em textos que focam a promoção da saúde. Apresenta os resultados de uma pesquisa de doutorado na qual foram analisadas cinco teses de doutorado e quatro dissertações de mestrado sobre a promoção da saúde. A partir dos referenciais de análise em torno das noções de dinâmica social, das racionalidades empregadas e das visões sobre o projeto da modernidade presentes no material pesquisado, pode-se interpretar as etiologias para a produção da noção de hipossuficiência do sujeito e, consequentemente, o lugar que essa produção reserva a ele.

Verificou-se uma ocorrência significativa dessa noção de hipossuficiência e sua aproximação ao cientificismo.

Palavras-chave: Promoção da saúde. Racionalidades. Sujeito. Conhecimento.
Elaborado com base em Fernandez (2011).

${ }^{1}$ Departamento de Prática de Saúde Pública, Faculdade de Saúde Pública, Universidade de São Paulo. Av. Dr. Arnaldo, 715, Cerqueira César, São Paulo. 01.246-904. juanfernandez@usp.br

${ }^{2}$ Departamento de Prática de Saúde Pública, Faculdade de Saúde Pública

Universidade de São Paulo. 


\section{Introdução: sujeito e hipossuficiência do sujeito}

A questão do sujeito tem sido, há muito tempo, objeto de interesse da filosofia e das ciências humanas e sociais. Este artigo analisa o sujeito em "relação com o mundo" (Abbagnano, 1961, p.932), a partir dos dados obtidos em pesquisa (Fernandez, 2011), que investigou a forma como essa relação foi considerada na elaboração de teses e dissertações sobre promoção da saúde em diferentes universidades. O percurso investigativo partiu das considerações de Minayo (2001), que discute a ideia de sujeito a partir do foco da sociologia. Para essa autora, "dentro de posições e premissas diferentes, consciente ou inconscientemente, todos os pensadores sociais trabalham a temática da estrutura e do sujeito, ou seja, das permanências e das transformações" (Minayo, 2001, p.8, grifos da autora).

Nesse texto, a autora destaca a pouca convergência sobre o que seja o sujeito para as diferentes teorias sociológicas clássicas, e destaca, também, as diferenças existentes dentro de uma mesma corrente de produção desses conhecimentos, sendo comum a todas elas a consideração da relação entre determinismo e protagonismo histórico.

Tomamos como referência, também, as considerações de Ayres $(2001$, p.64) relativas à noção de sujeito como "um elemento conceitual que está no centro das mais progressistas proposições no campo da saúde na atualidade". Esse autor, que parece tratar desse sujeito "relação com o mundo", destaca a ideia do "caráter imediatamente relacional e irremediavelmente contingente de nossas identidades e historicidades como indivíduos e grupos" (Ayres, 2001, p.65).

Tal ideia nos interessa em dois sentidos. Primeiramente, no que concerne ao caráter contingente das construções identitárias, em razão da importância que atribuímos a essa qualidade na contemporaneidade. Em segundo lugar, mas não com menos importância, interessa-nos o caráter relacional e móvel de tais construções identitárias que, como entendemos, contrapõe-se à ideia de uma fixação de identidades, um ponto a partir do qual podemos introduzir a questão da hipossuficiência do sujeito.

Acreditamos poder pensar sobre a fixação de identidades como uma etiologia e uma expressão, entre outras, da noção de hipossuficiência do sujeito, isto é, do entendimento do sujeito como desprovido de capacidades. Tratar-se-ia, nesse caso, de uma identificação atribuída como uma característica essencial e permanente do outro. Tal fixação, e fazendo uso de uma metáfora, não apenas mede um sujeito com a régua daquele que mede - ignorando a multiplicidade das réguas, inclusive aquela do sujeito medido -, mas o faz de forma definitiva - desconsiderando qualquer possibilidade de extensão ou contração ao longo do tempo e da experiência desse mesmo sujeito. Ou seja, isso retira do sujeito sua capacidade de construção permanente da própria identidade.

Comporiam essa fixação de identidades uma atitude etnocêntrica (Rocha, 1989), quando se escolhem os critérios para "medir" o outro, e uma desconsideração da capacidade humana de ação e discurso (Arendt, 1995), quando não se espera que o sujeito diga quem ele é, de fato. Como consequência de tal fixação, sujeitos são reduzidos a uma de suas características ou estados, como ser o sedentário, o hipertenso ou o idoso, quando não, e de modo mais grave, essa redução enseja a produção de estigmas (Goffman, 1980), isto é, a construção de identidades deterioradas para o outro.

Como destaca Ayres, contrapondo-se a essa perspectiva, "o que permanece no tempo não é sempre um e mesmo predicado que nos define como sujeitos, mas uma auto-diferenciação que se afirma a cada vez que reconheço um outro" (Ayres, 2001, p.66). Nesse sentido, e isso nos parece relevante, o sujeito estaria ativamente presente na construção de sua identidade, de sua saúde e, para manter o vocabulário utilizado por esse autor, presente na construção de seu projeto de sucesso prático (Ayres, 2007).

Também em Minayo (2001) encontramos referências à produção da noção de hipossuficiência em torno de outra etiologia. Segundo essa autora, "em termos gerais podemos inferir que o conhecimento médico e da saúde pública têm sido sistematicamente marcados pelo apagamento do sujeito" (Minayo, 2001, p.15), ou pelo que nós pretendemos denominar de produção de sua hipossuficiência. A autora destaca como causas para isso o positivismo do século XIX, quanto à consideração da "previsibilidade dos processos patológicos e o viés marxista [que] frequentemente privilegiou a mudança de estruturas como a salvação para o setor" (Minayo, 2001, p.15). As causas, nesse caso, seriam fundamentadas pela 
descoberta e certeza em relação às "leis" que regem a vida tanto no sentido biológico quanto no social, econômico ou político, e que não é, por essa razão, perturbada pela ação dos sujeitos.

Para explicitar a questão de fundo subjacente a esse entendimento sobre o apagamento do sujeito, agregamos as considerações de Santos B.S. (2004, p.17), em seu esforço para aprofundar o "debate sobre a ciência enquanto forma de conhecimento e prática social", denunciando o papel desempenhado pela ciência ocidental moderna na ocultação de experiências, o que significa tornar irrelevantes "outros discursos ou narrativas sobre o mundo [...], [outras] formas de interação entre a cultura e o conhecimento [...], [enfim,] esconder ou desacreditar as alternativas" (Santos, 2004, p.778).

Em direção semelhante, Paula Carvalho (1987, p.50), ao comparar os paradigmas da simplificação e da complexidade - o paradigma clássico, científico e o paradigma holonômico - refere-se à instalação de uma "razão clássica" como um ato político de eliminação de "toda desordem e toda subjetividade". Entendemos que declarar a "não-existência" ou eliminar "toda desordem e toda subjetividade" corresponde, também, a definir um lugar para os sujeitos que é o lugar da "hipossuficiência", produzida, nesses casos, por essa racionalidade dominante ou clássica.

O que este artigo pretende, portanto, discutir é a ocorrência de formas de considerar a promoção da saúde - para indivíduos e grupos - que parecem prescindir da ação ou participação dos sujeitos a quem se dirigem as intervenções em promoção da saúde.

Essa discussão é importante à medida que os documentos de referência da promoção da saúde contemporânea apregoam a ideia de que os sujeitos sejam, também, responsáveis por sua saúde (Westphal, 2006; WHO, 1998).

Localizamos tal contemporaneidade nos anos de 1980, e, em particular, na I Conferência Internacional sobre Promoção da Saúde, realizada em 1986, em Ottawa, Canadá, que oferece novo marco de referência dessa área para o mundo todo. A Carta de Ottawa (Brasil, 2001) define promoção da saúde como processo de capacitação dos indivíduos e coletividades para identificar fatores e condições determinantes da saúde e exercer controle sobre eles, de modo a garantir a melhoria das condições de vida e saúde. Dezoito anos mais tarde, esse entendimento continua prevalecendo, como se pode observar nas considerações de Campos et al. (2004, p.747) a respeito de que “... uma Política Nacional de Promoção da Saúde terá maior eficácia à medida que construa ações quanto aos modos de vida que apostem na capacidade de auto-regulação dos sujeitos sem que isso signifique a retirada das responsabilidades do Estado quanto às condições de vida...".

Importa reter que esse referencial, que dirigiu o foco para o controle dos determinantes sociais, econômicos e políticos do processo saúde-doença (CNDSS, 2008; Zioni, Westphal, 2007; Buss, 2000), pôde conduzir a promoção da saúde para uma preocupação com as condições de emprego, renda, moradia, educação e segurança, entre outras, que facilitam ou dificultam, às pessoas e comunidades, a obtenção de graus satisfatórios de saúde e bem-estar (Brasil, 2006). O mesmo referencial, no entanto, pôde ensejar, também, não uma guinada em relação aos determinantes sociais da saúde, mas a um foco nos comportamentos e estilos de vida saudáveis que indivíduos ou populações deveriam eleger.

O desenvolvimento da promoção da saúde, quer numa ou noutra dessas alternativas acima, teria de enfrentar, segundo entendemos, a questão da capacidade de agência dos sujeitos na produção de sua saúde, pois, como assinalado por Fleury-Teixeira et al. (2008, p.2115), "a ampliação da autonomia, vista como ampliação das capacidades e possibilidades de escolha das pessoas, é a categoria central e o critério definidor da atuação em promoção de saúde". No primeiro caso, teria de refletir sobre o tipo de relações que se estabelece entre os sujeitos e as estruturas e, no segundo caso, sobre a legitimidade das escolhas dos sujeitos em relação a seus estilos de vida.

Ao se realizar tais enfrentamentos ou fazer tais reflexões, põem-se à prova, por assim dizer, os entendimentos que se tem, de fato, sobre o discurso acerca da responsabilidade que o sujeito tem sobre sua saúde.

O que levou ao desenvolvimento de nossa pesquisa foi a percepção de que tanto na reflexão quanto na prática em promoção da saúde, frequentemente - e não obstante a manutenção desse discurso de responsabilidade ou corresponsabilidade -, o sujeito apareça sobredeterminado pelas estruturas ou culpabilizado por suas escolhas, ou seja, como incapacitado para agir e para tomar as decisões corretas relacionadas a sua condição de vida e a sua saúde. 


\section{Referenciais da análise}

Nossa perspectiva para abordar a problemática relativa ao lugar que parecem ocupar os sujeitos, na produção teórica selecionada para este estudo, partiu da noção de dinâmica social e de seus enlaces com a racionalidade empregada e com uma visão acerca da modernidade e contemporaneidade presentes no material de pesquisa, segundo nossa análise e interpretação.

\section{Dinâmica social}

Arrolamos diferentes abordagens para a dinâmica social, tais como: a formulação positivista da estática e da dinâmica sociais (Comte, 1978); o conflito entre as forças produtivas e as relações de produção (Marx, Engels, 1980); a passagem da solidariedade mecânica à orgânica com a divisão social do trabalho (Durkheim, 1999); e a dinâmica entre o instituído e o instituinte (Castoriadis, 2000) em cotejamento às anteriores. Cogitamos, apoiados nesta última abordagem, que a dinâmica social corresponde a diferentes formas de equacionamento das tensões em torno do binômio determinação/ autonomia na vida dos indivíduos e coletividades.

\section{Racionalidades}

O caminho que seguimos em nossa investigação encontra correspondências, também, na crítica geral de Santos B.S. (2004) acerca da racionalidade ocidental predominante, da qual tomamos, como aspectos mais significativos: o reducionismo analítico - decomposição do objeto em partes a serem estudadas; o mecanicismo - o estabelecimento de relações simples de causa-efeito, e uma objetivação, que separa sujeito e objeto de conhecimento. Chegamos, dessa forma, a uma racionalidade instrumental identificada com o "grau de acurácia com que se atinge fins" (Souza et al., 2010, p.1), e que define com clareza seus objetos. Como indicado por Silva (1997, p.4), " ... a natureza, e tudo que ela contém, passa de força a coisa. [...] Ora, o compromisso que assim se institui entre a atividade da razão e a passividade de um mundo de objetos redunda na completa identificação entre racionalidade e manipulação" (grifos do autor).

Esses elementos significativos, por sua vez, são acionados para produzir leis universais e a verdade que decorre das "ideias claras e distintas" - amalgamando, assim, o projeto cientificista de certeza, previsibilidade e controle.

Problematizamos essa racionalidade com a argumentação de Morin (2002, p.175), que desenvolve a ideia bachelardiana de que "não há nada simples na natureza, só há o simplificado", tornando a complexidade um desafio fundamental. Esse desafio pode ser resumido da forma que segue:

a) Irredutibilidade do acaso e da desordem; b) transgressão dos limites da abstração universalista; c) mistura de interações e inter-retroações dos fenômenos biológicos e sociais; d) uma relação complementar e antagonista entre as noções de ordem, desordem e organização; e) constatação de que o todo não é igual à soma das partes e onde as organizações são a um só tempo acêntricas, policêntricas e cêntricas; f) princípio de organização recursiva que coloca o problema da auto-produção e da auto-organização; g) crise dos conceitos fechados e claros como um sinal de verdade; h) o observador-conceptor deve se integrar na sua observação e na sua concepção; e, i) aceitar a contradição (entre duas noções que se tornaram complementares, por exemplo). (Morin, 2002, p.177-87)

\section{Modernidade e contemporaneidade}

Priorizamos a discussão sobre modernidade e contemporaneidade como expressão de mudanças significativas nos quadros mentais das culturas do Ocidente, isto é, de um "espírito do tempo, ou uma espécie de ambiência que se mostra nos modos de pensar, de organizar, de sentir" (Rouanet, Maffesoli, 1994, p.26). 
Para uma leitura sobre a modernidade, baseamo-nos nas considerações de Bauman (1999), que se refere a uma luta contra a ambivalência, como marca característica desse período. Essa luta é, segundo ele, a da construção da "ordem como tarefa [...] como o arquétipo de todas as outras tarefas [... sendo que] o outro da ordem não é uma outra ordem: sua única alternativa é o caos" (Bauman, 1999, p.12-4, grifo do autor).

A importância de considerarmos essa luta contra a ambivalência resulta do que são as consequências dessa prática moderna. Diz Bauman (1999, p.16): "a construção da ordem coloca os limites à incorporação e à admissão. Ela exige a negação dos direitos e das razões de tudo que não pode ser assimilado - a deslegitimação do outro". Como se pode perceber, tal argumentação corrobora para o exame que nos interessa da produção de hipossuficiência dos sujeitos, neste caso, deflagrada por visões de mundo, ou pela paisagem mental de um período histórico.

Na perspectiva que traz esse autor, os contemporâneos teriam mais dificuldade para acreditar que apenas o "bom" uso da razão poderia conduzir-nos a uma sociedade mais solidária; que precisaríamos apenas avançar um pouco mais o desenvolvimento tecnológico; que, com mais engenharia institucional, lograríamos alcançar maior controle sobre a existência; que, no futuro, nossos problemas se resolveriam, ou, ainda, que o problema estaria naquele "outro" tão diferente de nós. Isso significa que está em crise um conjunto de valores que compuseram uma narrativa propriamente moderna.

\section{Metodologia}

Nossa perspectiva metodológica, que parte das considerações de Goldschmidt (1963), mas que as ultrapassa, consiste de uma sobreposição entre uma análise do tempo lógico, isto é, da estrutura lógica da argumentação presente em cada um dos documentos selecionados - quando são analisadas as "teses" e seu encadeamento na construção do texto -, e uma análise do tempo histórico, isto é, uma hermenêutica do texto, para interpretar/compreender seus pressupostos e conceitos.

Assumimos essa perspectiva baseando-nos na ideia de uma "filosofia do pormenor epistemológico" (Bachelard, 1974, p.25), que elege uma noção, buscando conceituá-la em diferentes perspectivas e intentando apreender as relações que estabelece com outras noções que tomam parte de sua constituição - como o enlace a que nos referimos anteriormente da "dinâmica social" com as "racionalidades" e as "visões sobre a modernidade".

Não se trata de uma revisão da literatura científica sobre o tema, mas de uma exploração dele: do lugar dos sujeitos e a questão da hipossuficiência nas ações de promoção da saúde, a partir de sua análise em uma amostra intencional de dissertações e teses, escolhidas aleatoriamente de um conjunto pré-selecionado a partir de algumas características, como indicado a seguir.

\section{O material de pesquisa}

Foram selecionadas, na base de dados "Lilacs" (http://bases.bireme.br/cgi-bin/wxislind.exe/iah/ online/? IsisScript=iah/iah. $x$ is\&base $=$ LILACS\&lang $=p$ ), teses e dissertações que continham o termo "promoção da saúde" no título e estavam disponibilizadas na rede mundial de computadores. A busca produziu 27 registros e, após leitura dos resumos, excluímos: os documentos que focavam alguma doença ou área da assistência em particular, a discussão de técnicas ou métodos, bem como as percepções e representações dos sujeitos de pesquisa. Excluímos, ainda, um documento de pesquisador com quem temos publicado, assim como um documento breve contendo apenas um levantamento bibliográfico. Chegamos, assim, às quatro dissertações e às cinco teses que compuseram nosso material de pesquisa.

\section{A interpretação sobre o lugar dos sujeitos}

Uma relação dinâmica entre a determinação e a autonomia na experiência dos sujeitos; uma complexidade inextinguível que dá lugar ao paradoxo e ao contraditório e exige o emprego de "outras" 
lógicas; e um contexto cultural de autoexame motivado pela eclosão da diversidade e contingência, como sumarizado acima, foi o referencial para nossa interpretação do material de pesquisa.

Para atingirmos nosso objetivo de apreendermos que lugar a produção científica selecionada atribui aos sujeitos na produção de saúde, consideramos, portanto, as formas mais autônomas ou mais heterônomas de os sujeitos se relacionarem com as instituições. Consideramos, também, o sujeito na sua relação com o mundo: produzindo permanências e, ou, transformações; como determinado e, ou, protagonista; como instituído e, ou, instituinte, sendo que as conjunções aditivas e alternativas aqui empregadas refletem uma abertura às perspectivas do "paradoxo" (Wunenburger, 1995) e do "inacabamento" (Lapassade, 1975).

\section{Análise e discussão}

Vejamos como nossa amostra pôde contribuir para a discussão acerca da produção da hipossuficiência dos sujeitos.

Santos (2004), em dissertação que avalia as potencialidades de programas de promoção à saúde na consolidação da proposta de cidade saudável, aproxima a situação contemporânea à experiência de crises social, econômica e ambiental, assim como indica a ocorrência de tensões paradigmáticas no que diz respeito aos modelos de desenvolvimento dos países e de atenção à saúde dos mesmos, em particular, o caso brasileiro.

A autora propõe uma superação da crise que atravessa o setor saúde "a partir da mudança da prática sanitária vigente pautada numa proposta racionalizadora da reforma setorial, a exemplo do que acontece na Europa, com vistas a incrementar a eficiência dos sistemas" (Santos, 2004, p.16).

Destaca-se em sua abordagem, segundo entendemos, um conjunto de medidas técnicas e organizacionais para a solução dos problemas por ela identificados, não sendo, portanto, a ação de sujeitos o que se requisita nessa abordagem. O sistema de atenção aparece como um objeto inerte e passivo, à espera apenas de uma ação racionalizadora, como parece ser sua proposta de intervenção baseada no equilíbrio, eficiência e estabilidade das cidades.

Como já indicamos, a partir de Silva (1997, p.4), "o compromisso entre a atividade da razão e a passividade de um mundo de objetos" - uma racionalidade instrumental - é o que parece sobressair na argumentação de Santos (2004). Assim, prevalece um "vocabulário" de eficiência, eficácia, relações custo/benefício e de competência técnico-científica.

Identificamos, nesse caso, uma perspectiva de hipossuficiência do sujeito que resulta da ampla objetivação do "mundo", que o coloca sob a manipulação e o domínio da técnica e, também, da ciência.

Cohen (2004), em tese que propõe a incorporação do conceito de habitação saudável dentro da estratégia da promoção de saúde mediante a reflexão e desenvolvimento do conceito de habitabilidade, parece-nos corroborar essa perspectiva de hipossuficiência do sujeito.

O lugar que ocupam, de fato, os sujeitos em sua argumentação não aparece vinculado a qualidades - quaisquer que sejam - destes ou à sua capacidade de agência. As aspirações, desejos, prioridades e valores dos agentes que participam da construção do espaço urbano deveriam se dobrar às razões técnicas. É uma racionalidade instrumental o que preside, nessa abordagem, a adoção de "medidas corretivas, para se instaurar novamente o equilíbrio ecológico" (Cohen, 2004, p.22).

Como diz a autora,

... a técnica evoluiu com uma velocidade quilométrica, em busca da ruptura das limitações originalmente impostas ao indivíduo, trazendo avanços inexoráveis e fazendo valer a força da racionalidade em busca da nossa sobrevida. Passando, dessa forma, a técnica a executar, o racional a comandar e cada ação estar embasada na racionalidade da sobrevida de nosso ambiente e da nossa vida, dois marcos que poderiam se completar e promover a saúde humana e ambiental. (Cohen, 2004, p.117) 
A essa exaltação da técnica e da racionalidade só poderia corresponder o que está do outro lado - a experiência humana comum e ordinária -, a condição de "errante", como indicado no excerto abaixo, ou de hipossuficiente, como tentamos definir. Vejamos se não são "errantes" aqueles sujeitos

... deserdados da sorte, aos quais os avanços do progresso não chegam; bafejados pela sorte que teimam em ignorar os riscos da exclusão do outro; burocratas do aparelho estatal, que no suposto afam [sic] de resolver o problema habitacional, sufocam os legítimos desejos dos carentes em participar na sua libertação e acadêmicos que não conseguem vencer o desafio de colocar a teoria em prática. (Cohen, 2004, p.93)

À precariedade dos sujeitos, no caso de Santos (2004), e sua condição de "errantes", no caso de Cohen (2004), podemos acrescentar a ideia de que a ação dos sujeitos pode ser considerada "falsa", como no caso de Castro (2004), em sua Dissertação, que discute as matrizes discursivas da promoção da saúde e suas relações com a comunicação, tendo por objeto uma coluna de jornal de grande circulação.

Uma visão crítica em relação à proposta da promoção da saúde, ao que ela representa e ao que ela tem se ocupado em fazer é o que permite à autora chegar a um entendimento do que seja o sujeito da promoção da saúde. Diz ela que

Há, portanto, uma confluência de interesses na interface promoção da saúde - meios de comunicação, na medida [em] que ambos priorizam a transferência de conteúdos a um público desinformado, que precisa obter informações para cuidar da sua saúde e adotar hábitos de consumo para mantê-la. (Castro, 2004, p.113)

É em razão dessa postura crítica que também os sujeitos profissionais de saúde ocupam o "lugar social [...] das normas e prescrições e o poder que dele emana" (Castro, 2004, p.117). Não parece ser, portanto, do poder dos sujeitos que sua argumentação trata, mas sim do poder do lugar ou das estruturas ocupadas por eles.

Seu argumento está apoiado em um modelo explicativo universalista, baseado nas leis da história, que parece conferir um elevado grau de previsibilidade ao transcurso da experiência social e, da mesma forma, um elevado grau de certeza quanto àquilo que, de fato, conta e, por conseguinte, aquilo que consiste em erro, aquilo que, por ser da esfera ideológica, engana - como as práticas de saúde.

A certeza das leis descobertas acaba por retirar do sujeito a construção, a seu modo, da história. Tal certeza parece prescindir da ação efetiva dos sujeitos ou da necessidade de apreender essa ação da forma como ela se dá.

Reunimos essas abordagens - de Santos (2004), Cohen (2004) e Castro (2004) - como componentes ou representantes do tipo racionalista científico. As argumentações, nesses casos, dão-se sem qualquer recurso ao pensamento complexo ou às críticas e/ ou desafios que ele porventura apresente.

Lopes (2008), em tese que identifica as categorias de empowerment, participação e dialogicidade, a partir da Teoria Educacional Crítica (TEC), nas Cartas e Declarações sobre Promoção da Saúde, realiza um esforço de ampliar as bases teóricas de referência na crítica à racionalidade instrumental, mas persiste na base de sua argumentação um modelo explicativo racionalista, universalizador e "objetivizante".

Aparentemente, sua tomada de "empréstimo" (Lopes, 2008, p.51) da Teoria Crítica, ou o "insight" (p.54) que essa representa para alguns teóricos da Teoria Educacional Crítica, não cumpre uma tarefa, por assim dizer, da primeira. Essa tarefa, indicada por Giroux (1986 apud Lopes, 2008, p.42), "refere-se à natureza de crítica autoconsciente e à necessidade de se desenvolver um discurso de transformação social e de emancipação que não se aferre dogmaticamente a seus próprios princípios doutrinários". A certeza que a autora parece ter em relação ao modelo que explica quem deve fazer o que, e como, não convida a um exame crítico dessa natureza.

O lugar do sujeito parece fixado em torno da ideia da sujeição em correspondência à fixação de uma identidade de dominado e/ ou explorado. Como indica a autora, "... o educador crítico reconhece 
a necessidade pedagógica de 'capacitar' no sentido de formação/construção de poder aos estudantes para desenvolver a auto-reflexão e a consciência crítica sobre o contexto de exploração e dominação capitalista a que estão submetidos" (Lopes, 2008, p.51).

São limites à ação humana, nessa abordagem, "o avanço do poder integrador do capitalismo sobre a vida das pessoas" (Lopes, 2008, p.48), a imposição de "novos hábitos culturais com o objetivo de manter a saúde da força de trabalho e controlar as tensões sociais existentes na sociedade" (p.49) ou "a coerção auto-imposta [que impede que um...] grupo [...] possa perceber seus interesses" (p.46). O sujeito parece, portanto, ser aquele que se deixa manipular e que coage a si mesmo porque lhe falta o "esclarecimento". E é a certeza em relação a um saber totalizante - e esclarecido - a que aciona a fixação de uma identidade, para o sujeito, ao redor de sua condição de explorado, dominado e alienado, produzindo, assim, sua hipossuficiência.

A argumentação desenvolvida por Teixeira (2002), em dissertação que investiga o empoderamento de pessoas idosas a partir da participação em grupos de encontro direcionados à promoção da saúde, guarda semelhanças em relação à abordagem realizada por Lopes (2008).

Um conjunto de referências teóricas que atribuem importância à ação dos sujeitos também é apresentado por Teixeira (2002), mas o seu emprego não sugere a capacidade de os sujeitos produzirem, com autonomia, sejam os sentidos para sua experiência, sejam a construção ou reconstrução de seus mundos. Uma aludida qualidade de sujeitos parece, nesse caso, referida à capacidade que os sujeitos teriam de retificar seu conhecimento, precariamente baseado em costumes e tradições. A potência dos sujeitos é sua possibilidade de responder afirmativamente a uma intervenção educativa de correção.

Parece haver, assim, mais do que as construções identitárias pelos sujeitos, com caráter imediatamente relacional e irremediavelmente contingente, como indicado por Ayres (2001, p.65); há uma instrumentalização delas, que são, então, planejadas e têm algum propósito ou finalidade definida.

Aparentemente, não há, nessa argumentação, espaço para a incerteza, surpresa ou diferença. Já se sabe o que o sujeito é, o que pode e o que deve fazer. A crença na capacidade de moldar o outro parece tão intensa quanto o desejo de intervir ou manipular. O outro que está lá, nessas condições, é o que pensamos poder chamar, também, de hipossuficiente.

Esses casos - Lopes (2008) e Teixeira (2002) -, que relacionamos a um tipo racionalista com presença de complexidade, incluem os sujeitos na formulação de respostas, mas não necessariamente na formulação das perguntas, isto é, os sujeitos são tidos por capazes de cumprir a tarefa que a eles está reservada, mas não se considera que eles talvez sejam capazes de definir as próprias tarefas a cumprir. Subsiste a ideia de dadas condições objetivas - conhecidas mediante modelos científicos explicativos -, das quais os sujeitos devem tomar certo tipo de consciência.

Silva (2003), em tese que oferece o referencial "Comunidade Ampliada de Pesquisa" para uma promoção da saúde a partir do local de trabalho, desenvolve uma argumentação que escapa aos determinismos, dando lugar à criação de outras determinações construídas nas práticas cotidianas. Resistências, intencionalidades e escolhas, nessa perspectiva, produzem e são resultados da imprevisibilidade e dinamismo próprios à ação humana, à ação de sujeitos. Como assinala a autora,

O que os outros querem fazer de cada um, é o uso de si pelos outros [...]. Porém, o uso de si não se reduz àquilo que fazem de você, mas também aquilo que cada um faz de si-mesmo [...] o trabalho é sempre também uso de si por si, recentramento do meio de trabalho ao redor de seus possíveis singulares. (Silva, 2003, p.53)

Entretanto, esse reconhecimento do que é historicamente determinado, mas composto ou atravessado por antagonismos e contradições, não se aplica à experiência social de modo abrangente, mas apenas à esfera do trabalho e das relações que enseja. Quando não se trata dessa esfera, uma abertura ao indeterminado e contingente que a autora desenvolve em relação ao trabalho se esfuma.

Já não encontramos, então, aquilo que é "determinado por condições previamente estabelecidas, mas também pela dinâmica que se efetiva no processo" (Silva, 2003, p.54). Já não "há fugas, vazios, esquivamentos e resistências inesperadas" (p.27); não "há um engajamento do sujeito na relação de 
mediação" (p.34); e não há "também uso de si por si, recentramento do meio [...] ao redor de seus possíveis singulares" (p.53). Não há mais uma visão dos homens "como seres ativos na relação com o meio" (Silva, 2003, p.26), mas, sim, as "relações sociais do modo de produção capitalista vigente que condiciona todas as ações da sociedade" (p.205).

O que está em questão nessa argumentação não é a agência humana e/ou a subjetividade e, ou, seu caráter instituinte. O que parece estar em questão é o lugar do trabalho na experiência humana, lugar este, ímpar e inconfundível com o que resta. As qualidades instituintes são atribuídas ao trabalho e não aos sujeitos - para justificar seu lugar de destaque e importância.

Prevalece na argumentação da autora - e, assim, se esvai também o lugar de agente do sujeito um vocabulário da necessidade e, portanto, da "determinidade" (Castoriadis, 1987) em torno das "relações sociais do modo de produção capitalista vigente que condiciona todas as ações da sociedade" (Silva, 2003, p. 205), a despeito do que as experiências locais - como a que ela investiga - possam problematizá-lo ou relativizá-lo, produzindo, assim, a noção de hipossuficiência do sujeito.

As abordagens de Silva (2003), e a seguinte, apesar das semelhanças que apresentam em relação às anteriores, compõem um tipo distinto, no qual a argumentação baseada em seus objetos de estudos dáse em uma perspectiva complexa, ainda que tendam a considerar esses objetos mais singulares do que talvez o sejam.

Barros (2009), em dissertação que investiga os deslocamentos conceituais que caracterizam a ruptura paradigmática trazida pela promoção da saúde a partir do estudo de um caso de ação intersetorial, cogita "... um deslocamento da racionalidade instrumental - de construção de objetos para intervenção - para uma racionalidade hermenêutica/ intersubjetiva - aberta ao devir e ao compartilhamento - na forma de conceber saúde, sujeito e sociedade" (Barros, 2009, p.68).

A autora parece reconhecer a capacidade criativa e instituinte dos sujeitos em relação ao que está dado, instituído. Busca, assim, uma racionalidade diferente daquela que encontramos no paradigma científico clássico. No entanto, sua argumentação apresenta um conflito entre a dimensão compreensiva (construída na crítica ao racionalismo científico e sua lógica de "esclarecimento") e a dimensão crítica (que porta esse racionalismo da crítica pelo esclarecimento). Na síntese entre compreensão e crítica, o determinismo parece ser reposto.

A produção, nesse caso, de uma noção de hipossuficiência parece dar-se em torno da necessidade do recurso a um modelo explicativo universalista para validar um conhecimento, isto é, como uma espécie de concessão, na forma de reverência, ao cientificismo.

Outras duas pesquisas compõem um tipo racional complexo no qual não identificamos a produção da noção de hipossuficiência dos sujeitos. Esse é o caso de Assis (2004) - em tese que realiza uma avaliação de programas de promoção da saúde do idoso, na qual destaca qualidades de agência dos sujeitos, e o faz, também, a partir da crítica a uma racionalidade que prima pela tentativa de simplificação das realidades que parecem complexas, entre elas, as experiências dos sujeitos.

Identificamos, em seu argumento, o enfrentamento de vários dos elementos apresentados por Morin (2002), listados acima, como desafios da complexidade. A autora considera a irredutibilidade do acaso e da desordem, a transgressão dos limites da abstração universalista e a superação da ideia cartesiana de que a clareza e a distinção das ideias sejam um sinal de verdade. Sua abordagem aceita a contradição, a convivência de explicações diversas para um mesmo fenômeno, e considera uma causalidade complexa.

Dessa forma, pudemos encontrar um entendimento do sujeito como produtor de saúde - em uma relação dinâmica com as estruturas, sofrendo ações dela e atuando sobre a mesma.

Suas considerações acerca da produção de "novos sentidos para as experiências vividas" pelos sujeitos (Assis, 2004, p.3), da "capacidade que cada indivíduo possui para tolerar, enfrentar e corrigir aqueles riscos ou traições que inevitavelmente fazem parte da nossa história" (p.185-6) e do "engajamento ativo com a vida" (p.10) são alguns exemplos do lugar que ocupariam os sujeitos.

Cordeiro (2008), em Tese que procede a uma análise da formulação e implementação das políticas públicas no âmbito da estratégia "Cidade Saudável", apresenta uma lógica subjacente aos processos sociais - sejam eles a produção, difusão e apropriação de conhecimentos ou a criação e desenvolvimento de políticas públicas - baseada numa tensão entre polaridades e formas de 
equacioná-la, uma vez que "os processos instituintes podem ser de diversos graus, mas sempre estão em contraposição dialógica com o instituído" (Cordeiro, 2008, p.65).

Uma dinâmica social reticular, que emerge desse entendimento, rompe com a "divisão artificial entre ator e estrutura", e implica considerar que a experiência "tanto escapa ao imperialismo da obrigação coletiva como ao relativismo da liberdade individual" (Cordeiro, 2008, p.54).

O lugar do sujeito é apreendido, na abordagem que a autora desenvolve, no cerne dessa dinâmica social, que tem em sua argumentação um valor heurístico, já que apresenta o objeto de estudo e o qualifica, ao mesmo tempo em que orienta o modo de abordá-lo e condiciona os resultados da análise realizada sobre esse objeto.

Uma análise mais dinâmica que estrutural, baseada em sua visão reticular de dinâmica social, inscreve atores à medida que desmitifica o lugar da técnica nos processos sociais, razão pela qual, segundo a autora, "o papel dos atores é fundamental para que se compreendam as inovações políticas e/ou os processos de racionalização administrativa, equacionados mediante a compatibilização ou adequação de estratégias políticas" (Cordeiro, 2008, p.90).

\section{Considerações finais}

Ao final desta recuperação de nossos argumentos relativos ao lugar dos sujeitos na produção de saúde e de suas aproximações à noção de hipossuficiência dos sujeitos, identificamos uma presença significativa da noção de hipossuficiência do sujeito em nosso material de pesquisa. Cabendo destacar, porém, que, em alguns casos, essa noção apresenta certa ambiguidade e que, em outros, ela já não se aplica.

Em nossa investigação, os quatro tipos acima descritos referem-se ao perfil epistemológico (Bachelard, 1974) da noção de dinâmica social, isto é, aos graus de influência das diferentes partes componentes do espectro filosófico - racionalismo científico e racionalidade complexa - no pensamento de cada autor em relação a essa noção. Nesse sentido, os tipos decorrem da identificação de semelhanças em torno desses graus de influência.

Cabe reforçar que, por um lado, não se verifica a produção de hipossuficiência no tipo racional complexo, e que, por outro lado, a produção da noção de hipossuficiência parece irremediavelmente ligada à presença do racionalismo científico, independentemente dos graus em que este ocorra formando os três primeiros tipos apresentados.

Os esforços empreendidos por certa promoção da saúde em produzir saúde sem a participação do sujeito, seja prescrevendo-Ihe condutas, seja apenas ampliando o mercado de consumo de qualidade de vida, só parecem ser tão inócuos quanto os esforços críticos dirigidos a esse posicionamento, que mantêm a ideia da passividade do sujeito nas suas relações com o mundo. Da mesma forma, acreditar que o indivíduo tenha, com a promoção da saúde, a oportunidade de retificar seu conhecimento, substituindo tradições e costumes por evidências científicas, parece tão arrogante e "imobilizador" quanto a ideia de convencê-lo a respeito de sua completa submissão às estruturas.

Uma polêmica assentada nessas questões não oferece alternativa, de fato. Elas parecem presas ao mesmo paradigma e, dessa forma, tanto as propostas e desejos de transformação dos "promotores de saúde" quanto o esvaziamento disso pelos seus críticos se convertem apenas em um registro da sobrevida do cientificismo.

Por outro lado, a hipossuficiência dos sujeitos não é uma construção particular da promoção da saúde, mas, sim, uma questão que também ela deveria enfrentar. O contexto de emergência dessa área do conhecimento, afinal, é também o contexto de uma crise dos postulados do cientificismo, que desafia a progressão dos conhecimentos em todas as demais áreas. Nesse sentido, construir essa área baseando-se na crítica ao chamado paradigma biomédico das necessidades biológicas e do controle ou correção dos processos patogênicos pode ser pouco. Ainda mais quando, aparentemente, a alternativa proposta é a mera substituição de uma determinação dada pelo biológico por uma determinação dada socialmente.

As situações nas quais a produção teórica sobre a promoção da saúde se aproxima do desenho de uma alternativa são aquelas em que as tentativas de simplificação dão lugar à complexidade, a exemplo do que encontramos em parte do material de estudo utilizado. 
Tal passagem pode permitir uma superação das dicotomias em torno do sujeito e estrutura e, assim, o ingresso em uma perspectiva na qual a experiência social se dá em meio a uma relação entre o instituído e o instituinte. Dito de outra forma, na ação humana, há sempre o enfrentamento de alguma instituição, cujo desfecho talvez seja mais contingente e indeterminado do que o desejado por nossa tradição cientificista.

A pretensão que esta argumentação tem de contribuir para o desenvolvimento da área da promoção da saúde é a de colocar a questão da hipossuficiência nesses termos e demandar a ampliação dos conhecimentos em relação a ela e suas consequências, como uma das formas de realizar parte das "promessas" mais citadas por profissionais e pesquisadores no sentido da transformação e da inclusão. Como diz Bourdieu (2004, p.55), "a censura mais radical é a ausência", e podemos supor que ninguém pretenda produzir saúde a partir dela.

\section{Colaboradores}

Juan Carlos Aneiros Fernandez redigiu o texto do artigo; Marcia Faria Westphal orientou a pesquisa de Doutorado que deu origem ao texto e revisou-o para submissão.

\section{Referências}

ABBAGNANO, N. Dicionário de Filosofia. São Paulo: Martins Fontes, 1961.

ARENDT, H. A condição humana. Rio de Janeiro: Forense Universitária, 1995.

ASSIS, M. Promoção da saúde e envelhecimento: avaliação de uma experiência no ambulatório do Núcleo de Atenção ao Idoso da UnATI/UERJ. 2004. Tese (Doutorado) - Escola Nacional de Saúde Pública, Fundação Oswaldo Cruz, Rio de Janeiro. 2004.

AYRES, J.R.C.M. Uma concepção hermenêutica de saúde. Physis, v.17, n.1, p.43-62, 2007.

Sujeito, intersubjetividade e práticas de saúde. Cienc. Saude Colet., v.6, n.1, p.63-72, 2001.

BARROS, C.M.S. Mediação intersetorial para a promoção da saúde - o projeto Transando Saúde do SESC. 2009. Dissertação (Mestrado) - Escola Nacional de Saúde Pública Sergio Arouca, Rio de Janeiro. 2009.

BACHELARD, G. A filosofia do não. São Paulo: Abril Cultural, 1974. (Os Pensadores, v.38).

BAUMAN, Z. Modernidade e ambivalência. Rio de Janeiro: Jorge Zahar, 1999.

BOURDIEU, P. O poder simbólico. 7.ed. Rio de Janeiro: Bertrand Brasil, 2004.

BRASIL. Ministério da Saúde. Política Nacional de Promoção da Saúde. 2006. Disponível em: <http://portal.saude.gov.br/portal/arquivos/pdf/PNPS2.pdf>. Acesso em: 3 nov. 2010. 
BRASIL. Ministério da Saúde. Promoção da saúde: Declaração de Alma-Ata, Carta de Ottawa, Declaração de Adelaide, Declaração de Sundsvall, Declaração de Santafé de Bogotá, Declaração de Jacarta, Rede de Megapaíses e Declaração do México. Brasília: PNUD/Ministério da Saúde, 2001.

BUSS, P. Promoção da saúde e qualidade de vida. Cienc. Saude Colet., v.5, n.1, p.163-77, 2000.

CAMPOS, G.W. et al. Avaliação de política nacional de promoção da saúde. Cienc. Saude Colet., v.9, n.3, p.745-9, 2004.

CASTORIADIS, C. A instituição imaginária da sociedade. Rio de Janeiro: Paz e Terra, 2000. 1987.

Encruzilhadas do labirinto II: domínios do homem. Rio de Janeiro: Paz e Terra,

CASTRO, A.M.M. 'O melhor da vida': discursos da promoção da saúde na mídia impressa da cidade do Rio de Janeiro. 2004. Dissertação (Mestrado) - Escola Nacional de Saúde Pública, Fundação Oswaldo Cruz, Rio de Janeiro. 2004.

COHEN, S.C. Habitação saudável como caminho para a promoção da saúde. 2004. Tese (Doutorado) - Escola Nacional de Saúde Pública, Fundação Oswaldo Cruz, Rio de Janeiro. 2004.

COMISSÃO NACIONAL DOS DETERMINANTES SOCIAIS DA SAÚDE - CNDSS. As causas sociais das iniqüidades em saúde no Brasil. 2008. Disponível em: <http:// www.cndss.fiocruz.br/pdf/home/relatorio.pdf>. Acesso em: 1 dez. 2011.

COMTE, A. Catecismo positivista. São Paulo: Abril Cultural, 1978. (Os Pensadores).

CORDEIRO, J.C. Promoção da saúde e a estratégia de cidades saudáveis: um estudo de caso no Recife - Pernambuco. 2008. Tese (Doutorado) - Centro de Pesquisa Aggeu Magalhães, Fundação Oswaldo Cruz, Rio de Janeiro. 2008.

DURKHEIM, E. Da divisão do trabalho social. São Paulo: Martins Fontes, 1999.

FERNANDEZ, J.C.A. Promoção da saúde e dinâmica social: o lugar dos sujeitos. 2011 Tese (Doutorado) - Faculdade de Saúde Pública, Universidade de São Paulo, São Paulo. 2011.

FLEURY-TEIXEIRA, P. et al. Autonomia como categoria central no conceito de promoção de saúde. Cienc. Saude Colet., v.13, supl.2, p.2115-22, 2008.

GIROUX, H. Teoria crítica e resistência em educação. Rio de Janeiro: Vozes, 1986.

GOFFMAN, E. Estigma: notas sobre a manipulação da identidade deteriorada. Rio de Janeiro: Zahar, 1980.

GOLDSCHMIDT, V. A religião de Platão. São Paulo: Difusão Européia do Livro, 1963.

LAPASSADE, G. A entrada na vida. Lisboa: Edições 70, 1975.

LOPES, R.C. Promoção da saúde na perspectiva da Teoria Educacional Crítica: a relevância do empowerment, participação e dialogicidade. 2008. Tese (Doutorado) Departamento de Educação, Pontifícia Universidade Católica - Rio, Rio de Janeiro. 2008.

MARX, K.; ENGELS, F. Manifesto comunista. São Paulo: CHED, 1980.

MINAYO, M.C.S. Estrutura e sujeito, determinismo e protagonismo histórico: uma reflexão sobre a práxis da saúde coletiva. Cienc. Saude Colet., v.6, n.1, p.7-19, 2001.

MORIN, E. Ciência com consciência. Rio de Janeiro: Bertrand Brasil, 2002. 
PAULA CARVALHO, J.C. O imaginário e o pensamento organizacional na obra de Edgar Morin: seus fundamentos antropológicos. Rev. Fac. de Educ., v.13, n.1, p.43-89, 1987.

ROCHA, E.P.G. O que é etnocentrismo. 6.ed. São Paulo: Brasiliense, 1989.

ROUANET, S.P.; MAFFESOLI, M. Moderno x pós-moderno. Rio de Janeiro: UERJ, Departamento Cultural/SR3, 1994.

SANTOS, B.S. Conhecimento prudente para uma vida decente: um discurso sobre as ciências revisitado. São Paulo: Cortez, 2004.

SANTOS, E.R.R. Ações de promoção à saúde: caminho para a construção de uma cidade saudável? O caso do Recife. 2004. Dissertação (Mestrado) - Centro de Pesquisas Aggeu Magalhães, Fundação Oswaldo Cruz, Recife. 2004.

SILVA, E.F. Trabalhadores/as de escola e construção de uma "comunidade ampliada de pesquisa": a busca da promoção da saúde a partir dos locais de trabalho. 2003. Tese (Doutorado) - Escola Nacional de Saúde Pública, Fundação Oswaldo Cruz, Rio de Janeiro. 2003

SILVA, F.L. Conhecimento e razão instrumental. Psicol. USP, v.8, n.1, 1997. Disponível em: <http://www.scielo.br/scielo.php?script=sci_arttext\&pid=S0103-

65641997000100002\&lng >. Acesso em: 26 ago. 2010.

SOUZA, W.J. et al. Entre a racionalidade instrumental e a racionalidade substantiva: estudo sobre o dilema central do trabalho cooperativo. Disponível em: <http:// www.rizoma.ufsc.br/pdfs/96-of3-st1.pdf>. Acesso em: 26 ago. 2010.

TEIXEIRA, M.B. Empoderamento de idosos em grupos de Promoção da Saúde. 2002. Dissertação (Mestrado) - Departamento de Administração e Planejamento em Saúde, Fundação Oswaldo Cruz, Escola Nacional de Saúde Pública, Rio de Janeiro. 2002.

WESTPHAL, M.F. Promoção da saúde e prevenção de doenças. In: CAMPOS, G.W.S. et al. (Orgs.). Tratado de Saúde Coletiva. São Paulo: Hucitec, 2006. p.635-67.

WORLD HEALTH ORGANIZATION - WHO. Health promotion glossary. WHO/HPR/ HEP/98.1. Geneva: WHO, 1998.

WUNENBURGER, J-J. A razão contraditória: ciências e filosofia modernas: o pensamento do complexo. Lisboa: Instituto Piaget, 1995.

ZIONI, F.; WESTPHAL, M.F. O enfoque dos determinantes sociais de saúde sob o ponto de vista da Teoria Social. Saude Soc., v.16, n.3, p.26-34, 2007. 
FERNANDEZ, J.C.A.; WESTPHAL, M.F. El lugar de los sujetos y el tema de la hipo-suficiencia en la promoción de la salud. Interface - Comunic., Saude, Educ., v.16, n.42, p.595-608, jul./set. 2012.

El artículo analiza la noción de la hipo-suficiência del sujeto presente en los textos que se centran en la promoción de la salud. Presenta los resultados de una investigación doctoral que estudió cinco tesis doctorales y cuatro disertaciones de maestría en la promoción de la salud. Desde el análisis de referencia en torno a las nociones de la dinámica social, las racionalidades empleadas y visiones sobre el proyecto de la modernidad en el material de investigación se pudieron interpretar las etiologías para la producción de la noción de hipo-suficiência del sujeto y por lo tanto el lugar que le reserva esa producción. Hubo una incidencia significativa de esta noción de hiposuficiência y su acercamiento al cientificismo.

Palabras clave: Promoción de la salud. Racionalidades. Sujeto. Conocimiento. 